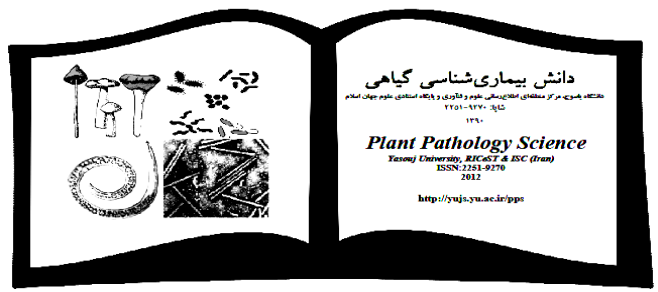

$$
\begin{aligned}
& \text { دانش بيمارىشناسى گياهى }
\end{aligned}
$$

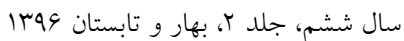

Plant Pathology Science

Vol. 6(2), 2017

\title{
A Review on the Application of Benzothiadiazole in Plant Diseases Management
}

\section{ZABIHOLLAH AZAMI-SARDOOEI ${ }^{凶}$, FARNAZ FEKRAT and FATANEH GHALAVAND}

Department of Plant Protection, University of Jiroft, Jiroft, Iran ( $\square$ Corresponding author: zabih.azami@gmail.com)

Received: 14.01.2017

Accepted: 30.07 .2017

Azami-Sardouei Z., Fekrat F. and Ghalavand F. 2017. A review on the application of benzothiadiazole in plant diseases management. Plant Pathology Science 6(2):33-42.

Abstract: The use of plant defense activators is a novel method of plant diseases management in recent years. Benzothiadiazole (BTH), is the first synthetic plant defense activator. In general, Benzothiadiazole has no direct effect against the pathogens, but it can activate the systemic acquired resistance (SAR) in plants, against a number of plant diseases. In addition, BTH widely is used to protect the plants against a range of pathogens on wheat, tomato, bean, tobacco, lettuce, banana and pears. In overall, Benzothiadiazole can be used as a safe and reliable product for plant protection and also as an alternative for chemical pesticides, which they have hazardous effects on environment.

Key words: Benzothiadiazole, Activator, Systemic acquired resistance

$$
\begin{aligned}
& \text { مرورى بر كاربرد بنزوتياديازول در مديريت بيمارىهاى تياهى } \\
& \text { ذبيحالله اعظمى ساردويى هـا فرناز فكرت و فتانه قلاوند } \\
& \text { كروه گياهيزشكى، دانشگاه جيرفت }
\end{aligned}
$$

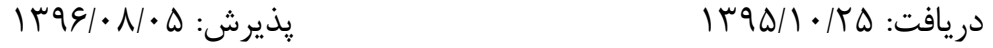

$$
\begin{aligned}
& \text { اعظمى ساردويى ذ.، فكرت ف. و قلاوند ف. و9¥ا. مرورى بر كاربرد بنزوتياديازول در مديريت بيمارىهاى }
\end{aligned}
$$

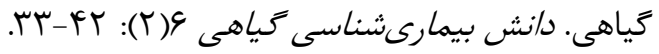

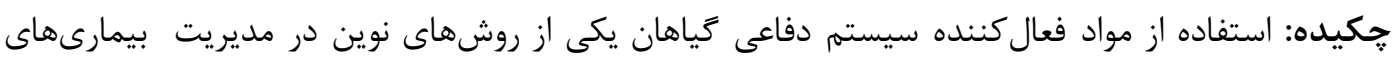

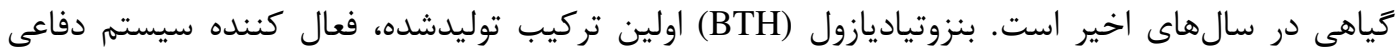

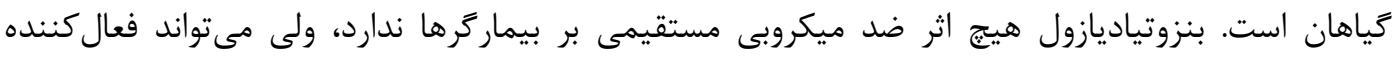

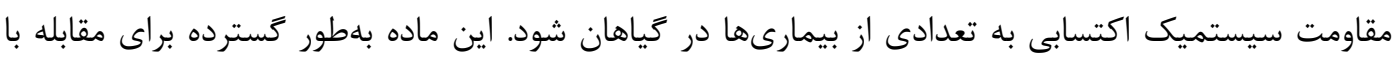

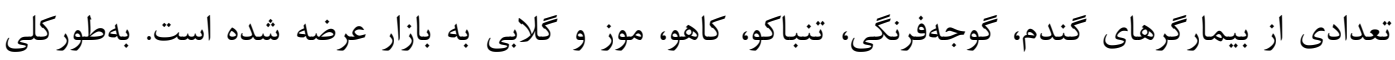

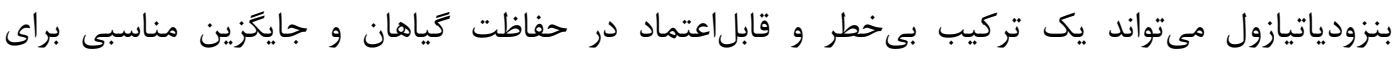

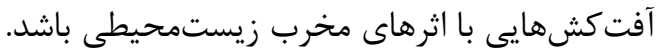

$$
\begin{aligned}
& \text { وازههاى كليدى: بنزوتياديازول، فعال كننده، مقاومت سيستميك اكتسابى }
\end{aligned}
$$


مقدمه

استفاده از فعال كنندهاى شيميايى خاص كه مىتوانند باعث ايجاد القاى مقاومت ( Induce (resistance در ₹ياهان شوند، در ساليان اخير در حال گسترش است (Azami-Sardooei 2011). جندين نوع از مواد فعالكننده مقاومت گَياهان ازجمله اسيد ساليسيليك، اسيد جاسمونيك، اتيلن، اسيدهاى جرب، متابوليتهاى ميكروبى، تركيبات مشتق شده از مخمرها و فعالكنندهاى شيميايى مانند بنزوتياديازول شناسايى شداند ـ هم:جنين تأثير ويتامين B2 يا ريبوفلاوين بهعنوان فعال كننده مقاومت گياهى روى (BTH) لوبيا عليه كيك خاكسترى به اثبات رسيده است (Azami-Sardooei et al. 2010). بنزوتياديازول در سال 19199 بهعنوان اولين فعال كننده مقاومت كياهان كشف شد كه باعث ايجاد ياسخهاى يكسان سريع بهعنوان Ruess et al. القاكننده مقاومت سيستميك اكتسابى (Systemic Acquired Resistance= SAR) مى 1996). در حقيقت اين ماده مشابه (آنالوگ) اسيد ساليسيليك است كه مىتواند دفاع سراسرى در برابر بيماركر را بدون تجمع اسيد ساليسيليك و با فعالسازى مسير پائيندست آن تحريك كند (Wang et al. 2007). اين تركيب شيميايى كه در ساليان اخير بهصورت تجارى در ارويا و آمريكا توليد و ثبتشده است، روى بسيارى از محصولات و درختان، تحت نامهاى تجارى ازجمله Bion@ در ارويا، Actigard@ در ايالاتمتحده آمريكا و Boost@® براى مقابله با بيماركرهاى متفاوت توصيه و بكار مىروند. بلهور كلى بنزوتياديازول هيج اثر ضدميكروبى مستقيم و قابلتوجهى را عليه بيماركرها نشان نمىدهد، بلكه در تحريك مقاومت گياه به بيمارىها بسيار مؤثر مىباشد و بهعنوان يك نوع تركيب پيشرفته حفاظتى گياهان به كار مىرود. بعلاوه BTH در كنترل بعضى از حشرات، كنهها، نماتدها و كياهان گل در گَونهاى مختلفى از گَاهان (غلات، سبزىها، درختان و گياهان تزيينى) بدون اثرات منفى به كار مىرود. هدف از نكارش اين مقاله ارايه و تحليل آخرين يزوهشهاى انجامشده در مورد كاربرد BTH در مبارزه با بيماركرهاى كياهى مختلف و برخى آفات مىباشد كه نتايج آنها بهصورت خلاصه در جدول ا آورده شده

\section{ا-تعريف و موقعيت فعال كنندههاى مقاومت در كياهان}

گياهان همجون ساير جانداران جهت مقابله با دشمنان داراى سيستمهاى ايمنى پيجٍيدهاى هستند و از 
سال ششم، جلد ז، بهار و تابستان و بـ

دانش بيمارىشناسى گياهى

Plant Pathology Science (ISSN:2251-9270) Yasouj University,RICeST \& ISC (Iran) Vol. 6(2), 2017

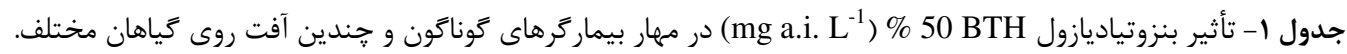

Table 1. Overview of the effect of BTH 50\% (mg a.i. /l), on several pathogens and pests on different plants

\begin{tabular}{|c|c|c|}
\hline $\begin{array}{l}\text { plant } \\
\text { plant }\end{array}$ & 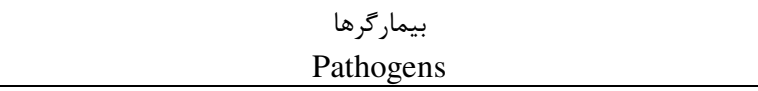 & $\begin{array}{c}\text { منابع } \\
\text { References }\end{array}$ \\
\hline Beans & $\begin{array}{l}\text { Botrytis cinérea, Fusarium oxysporum,Uromyces } \\
\text { appendiculatus,, Rhizoctonia solana, Colletotrichum } \\
\text { lindemuthianum, X. campestris }\end{array}$ & $\begin{array}{l}\text { Azami-Sardooei et al. 2013, } \\
\text { Iriti and Faoro 2003, Maffi et } \\
\text { al. 2010, Abdel-monaimet } \\
\text { et al. } 2011\end{array}$ \\
\hline Tomato & $\begin{array}{l}\text { Bemisia tabaci, Myzus persicae (Insecte), Meloidogyne } \\
\text { javanica, M. arenaria,Cucumber mosaic virus (CMV), } \\
\text { Tomato spotted wilt virus (TSWV), Orobanche } \\
\text { aegyptiaca, Pseudomonas syringae, X. axonopodis, F. } \\
\text { oxysporum, Phytophthora infestans, Botrytis cinerea }\end{array}$ & $\begin{array}{l}\text { Azami-Sardooei et al. 2013, } \\
\text { Abo-Elyousr et al. 2008, } \\
\text { Achuo et al. 2004, Boughton } \\
\text { et al. 2006, Audenaert et al. } \\
\text { 2002, Iriti et al. } 2007\end{array}$ \\
\hline Cucumber & $\begin{array}{l}\text { Botrytis cinerea, Colletotrichum orbiculare, } \\
\text { C.lagenarium, Sphaerotheca fuliginea, Pythium } \\
\text { ultimum, Cladosporium cucumerinum, }\end{array}$ & $\begin{array}{l}\text { Azami-Sardooei, et al. } 2013 \text {, } \\
\text { Bovie et al. } 2004\end{array}$ \\
\hline Lettuce & Erysiphe cichoracearum, Tetranychus urticae & Choh et al. 2004 \\
\hline Onion & Xanthomonas axonopodis pv. Allii & Lang et al. 2007 \\
\hline $\begin{array}{l}\text { Watermelon } \\
\text { and } \\
\text { Cantaloupe }\end{array}$ & $\begin{array}{l}\text { Didymella bryoniae, } \quad \text { Sclerotinia sclerotiorum, } \\
\text { Fusarium spp., Alternaria spp., Rhizopus spp. }\end{array}$ & Buzi et al. 2004 \\
\hline Pepper & $\begin{array}{l}\text { Phytophthora capsici, Xanthomonas axonopodis pv. } \\
\text { vesicatoria }\end{array}$ & $\begin{array}{l}\text { Yi et al. 2012, Baysal et al. } \\
2005\end{array}$ \\
\hline Potato & $\begin{array}{l}\text { Phytophthora infestans, Alternaria solani, Erysiphe } \\
\text { cichoracearum, Fusarium semitectum }\end{array}$ & $\begin{array}{l}\text { Kumar et al. 2011, Bokshi et } \\
\text { al. } 2003\end{array}$ \\
\hline Strawberry & Sphaerotheca macularis, Botrytis cinerea & $\begin{array}{l}\text { Hukkanen et al. 2008, Terry } \\
\text { and Joyce } 2000\end{array}$ \\
\hline $\begin{array}{l}\text { Wheat and } \\
\text { Barley }\end{array}$ & $\begin{array}{l}\text { Blumeria graminis, Fusarium pseudograminearum, } \\
\text { Pathogen-free }\end{array}$ & $\begin{array}{l}\text { Gorlach et al. } 1996 \text {, Desmond } \\
\text { et al. } 2008\end{array}$ \\
\hline Red clover & Orobanche minor & Kusumoto et al. 2007 \\
\hline Soya & $\begin{array}{l}\text { Rhizoctonia solani, Sclerotinia sclerotiorum, } \\
\text { Rotylenchulus reniformis and Meloidogyne javanica }\end{array}$ & $\begin{array}{l}\text { Chinnasri et al. 2003, Faessel } \\
\text { et al. } 2008\end{array}$ \\
\hline Sunflower & Orobanche cumana, Puccinia helianti & $\begin{array}{l}\text { Buschmann et al. 2005, } \\
\text { Amzalek and Cohen, } 2007\end{array}$ \\
\hline Tobacco & $\begin{array}{l}\text { B. cinerea, Ps. syringae, Thanatephorus cucumeris, } \\
\text { Cercospora nicotianae, Oidium neolycopersici }\end{array}$ & $\begin{array}{l}\text { Achuo et al. 2004, Friedrich } \\
\text { et al. } 1996\end{array}$ \\
\hline $\begin{array}{l}\text { Cabbage and } \\
\text { Rapeseed }\end{array}$ & $\begin{array}{l}\text { Peronospora parasitica, Rhizoctonia solani, } \\
\text { Orobanche ramose }\end{array}$ & Veronesi et al. 2009 \\
\hline Cotton & Thielaviopsis brasicola & Mondal et al. 2005 \\
\hline Pineapple & Meloidogyne javanica, Rotylenchulus reniformis & Chinnasri et al. 2006 \\
\hline $\begin{array}{l}\text { Ornamental } \\
\text { plants }\end{array}$ & $\begin{array}{l}\text { Botrytis cinerea, Peronospora hyoscyami } f . \quad s p . \\
\text { Tabacina, F. oxysporum f. sp. Cyclaminis }\end{array}$ & Dinh et al. 2008 \\
\hline Peach & Penicillium expansum & Liu et al. 2005 \\
\hline $\begin{array}{l}\text { Apple } \\
\text { Pear }\end{array}$ & Erwinia amylovora & $\begin{array}{l}\text { Mehrabipour et al. 2010, } \\
\text { Brisset et al. 2000, سرهنگى } \\
\text { Irqץ }\end{array}$ \\
\hline Citrus & Diaporthe citri, Elsinoe fawcettii, Alternaria sp & Agostini et al. 2003 \\
\hline
\end{tabular}


طرف ديكر القاى مقاومت سيستم طبيعى آنها را فعال مى كند. القاى مقاومـت در حقيقـت افـزايش مقاومـت كياهانى است كه در شرايط معمولى به بيمارى غير متحمل هستند اما بدون اينكـه در سـاختار زنتيكى ايسن كَياهان تغييراتى داده شود در برابر بيمارىها از خود مقاومت نشان مىدهند. بهعبـارتديخـر، مقاومست القـايى يك حالت فيزيولوزيكى از بهبود و ارتقاء ظرفيت دفاعى گياه، همراه بابيان زنها است كه بهوسيله محركهـاى محيطى غيرزنده و يا زنده مشخص القا مىشود و از طريق آنها يتانسيل سدهاى دفاعى ذاتى گيـاه در مقابـل برخى عوامل بيمارىزا فعالتر مىشوند. در مقاومت القايى يك محرك واكنش دفاعى گياه را در برابـر بيمـاركر ازنظر زمان يا مقدار تا جند برابر افزايش مىدهد و لذا درجه بالاترى از مقاومت در مدتزمان كوتاهتـرى ظـاهر مىشود. دو روش مهم كه بر روى القاى مقاومت تأكيددارند شامل SAR و ISR در شكل ا بهصورت شماتيك نشان دادهشهاند. مقاومت القايى سيستميك (ISR) توسط باكترىهاى افزايشدهنده رشد گيـاه معـروف بـهـ (Plant Growth Promoting Rhizobacteria= PGPR) ايجاد مىشود (Audenaert et al. 2002). بهعبارتديكر در مقايسه با نـوع ديخــر مقاومست، درنتيجـهـ تجمـع و ماندكارى گونههاى خاصى از ريزوباكترىها روى ريشه كياه توسعه مىيابد و واسـهه مسـير آن اتسيلن (ET) و اسيد جاسمونيك (JA) مىباشد(Pieterse et al. 2009). اما مقاومت القـيى اكتسـابى (SAR) توسـط عوامـل زنده و غيرزنده ازجمله تركيبات شيميايى مانند بنزوتياديازول فعالشده و در ارتباط با سازوكارهاى ييامدهنده

Non pathogenesis افزايش توليد و تجمع اسيد ساليسيليك و يروتيينهاى تنظيممننده دفاع كَياه موسوم بـــ related protein 1 (NPR1)

\section{r-كاربرد بنزوتياديازول در مديريت بيمارىهاى كياهى}

طبق يزوهشهاى انجامشده بنزوتياديـازول كـه از مشـتقات Acibenzolar-S-methyl بانـام شـيميايى 2,1,3-Benzothiadiazole-7-carbothioic acid S-methyl ester بلهنوان يكراه حل مناسب و كاربردى در مديريت بيمارىهاى كياهان محسوب مىشـود. BTH داراى دامنـه Friedrich et al. 1996, ) تأثير وسيعى روى عوامل بيمارىزاى گياهى ازجمله قارجها، باكتريها و ويروسها است 2009

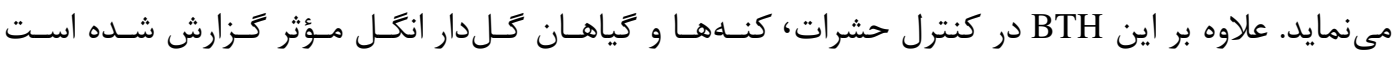


(Boughton et al. 2006, Kusumoto et al. 2007) از طـرف ديخــ در دهـه اخيـر تركيـب BTH بــاضـافه مانكوزب براى استفاده عليه بيمارىهاى محصولات كشـاورزى مختلـف بـهويـزه ســبزىهـا در آسـيا بـه بـازار عرضهشده است. همجنين از اين تركيب روى گياه موز بانام تجارى ثبتشده Boost جهت استفاده در مديريت قارج.Mycosphaerella fijiensis Morelet عامل بيمارى سيخاتوكاى سـياه مـوز اسـتفاده مسىشـود. كـاربرد بنزوتياديـازول (BTH) بـراى فعـال كـردن تعـدادى از زنهــاى مـرتبط بــاـSAR روى تنبــاكو، كنـدم، سـويا، سيبزمينى، نخود و سيب منجر به افزايش حفاظت كياهان در برابر عوامـل بيمـارىزاى مختلـف شــه اسـت . همجنين اين فعال كننده شيميايى باعث افزايش مقاومت در برابر حشره Bemisia tabaci Gen در بوتههـاى

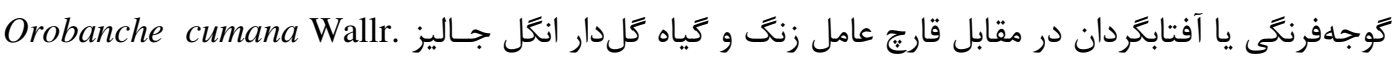
شده است (Buschmann et al. 2005). كاربرد و القاى مقاومت توسط BTH همجنين باعث مهار بيمارىهـاى مختلف در مركبات، سيب، گلابى، به لوبيا، كلم و بيمارىهاى ديگر گياهان شده است. يزوهشها نشان دادهاند كه BTH قادر به مهار بيمارىهاى يس از برداشـت نيـز هست (Terry and Joyce 2004 Liu et al. 2005,). لازم به ذكر است كه استفاده از اين تركيب در مهار بيمارىها، بهصورت اضافه كردن در خــاك اطـراف ريشـه، همراه آب آبيارى و يا ياشيدن روى بخشهاى هوايى كياه است. در بيشتر موارد BTH بـهكـاربرده شـده روى

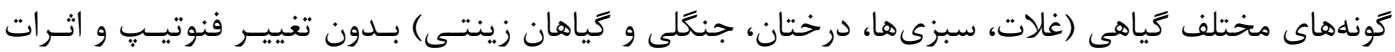
منفى كياهسوزى و كـاهش محصـول همـراه بـوده است ) , Desmond et a,l. 2008, Friedrich et al. 1996, Choh, 2004 ). ميزان غلظت مصرفى BTH مورد ارزيابى قراركرفته است كه كمترين آن روى لوبيـا بـا آץ.. ميلى گرم در ليتر عليه . Colletotrichum sp و بيشترين آن روى گندم رقم Kennedy با 9 •. آ ميلى ليتر عليه . Fusarium sp. بكار رفته است. امـا در خصـوص اثـرات منفـى كـاربرد بنزوتياديـازول روى كياهـان مختلف، بيشترين مقدار كَياهسوزى در بخش رويشى آفتابخردان و كمتـرين آن در بخـش زايشى روى كنـدم كزارششده اسـت(Desmond et al. 2008, Iriti and Faoro 2003). طـى يـك يـزوهش، كـاربرد BTH روى بخش هوايى گَوجهفرنگى در غلظت • ا ميلى گرم در ليتر بهخوبى بيمارى كيك خاكسترى را مهار نموده است،

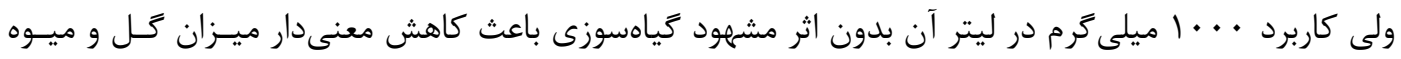
گوجهفرنگى در سطح ه درصد گرديد (Azami-Sardooei et al. 2013). 
بنزوتياديازول، گياه انكل گل جاليز را كه تاكنون روش قطعى براى مهار آن وجود ندارد، با غلظت كمتر

از · ا ميلى گرم در ليتر روى گوجهفرنكى، بهخوبى توانسته مهار كند و سازوكار عمل آن با انجام آزمايشهاى آنزيمى به اثبات رسيده است (مطالب منتشرنشده نغارندگان). نتيجه كيرى و وييشنهاد

بهطور خلاصه، يافتههاى حاصل از مرور اين تحقيقات نقش نوينى را براى بنزوتياديازول در فعالسـازى

سيستم ايمنى و ياسخهاى دفاعى كياهان تشريح مىنمايد. BTH قادر به القاى مقاومت عليه دامنه وسـيعى از بيماركرهاى گیاهى است كه نويدبخش آيندهاى بهتر در مديريت آفات و بيمارىهاى گياهى مىباشد. از طـرف ديكر ارجحيت اين تركيبات بر ريزوباكترها و ساير عوامل ميكروبسى متعـارض، يايـدارى اثر آنهـا در شـرايط مختلف محيطى است، جراكه باكترىها و ديكر عوامل زنده القاكننده مقاومت در برخى شرايط قـادر بـهـ بقـا و اعمال اثر القاكنندگى مقاومت نيستند. بِيشرفتهـاى كنـونى و آينـده، درك مـا را از تـأثيرات مختلـف BTH بهعنوان تركيب قابلاطمينان در مديريت سيستمهاى كشاورزى و تسهيل در پيشبرد اهداف كشـاورزى يايسدار افزايش مى دهد. بنابراين كاربرد اين تركيب همراه با استفاده از واريتههاى نسبتاً مقاوم و قارجكشهاى متـداول مى تواند بهعنوان يك روش نوين و دوستدار محيطزيست كه موجب تقويت سازوكارهاى دفــاعى گيـاه و نهايتـاً كاهش شدت بيمارىها و خسارت آنها مى گردد، يِيشنهاد مىشود.

\section{References}

ا. سرهنگى ن.، شكيب ع. م.، كشاورزى م.، ابراهيمى م.ع. و احمدراجى م. عqسا. تاثير ماده محرك BTH بر

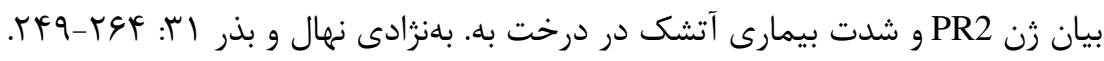

2. Abdel-monaim M. F., Ismail M. E. and K. M. Morsy. 2011. Induction of systemic in soybean plants against Fusarium wilts disease by seed trestment with benzothiadiazole and humic acid. Microbiology 39:290-298.

3. Abo-Elyousr K. A., and El-Hendawy H. H. 2008. Integration of Pseudomonas fluorescens and acibenzolar-S-methyl to control bacterial spot disease of tomato. Crop Protection 27:1118-1124.

4. Achuo E., Audenaert K., Meziane H. and Höfte M. 2004. The salicylic acid-dependent defence pathway is effective against different pathogens in tomato and tobacco. Plant Pathology 53:65-72. 
5. Agostini L., Martinon F., Burns K., McDermott M. F., Hawkins P. N. and Tschopp J. 2003. NALP3 forms an IL-1 $\beta$-processing inflammasome with increased activity in Muckle-Wells autoinflammatory disorder. Immunity 20:319-325.

6. Alishiri A. and Rakhshandehroo F. 2014. The role of salicylic acid in plant resistance against plant pathogens. Plant Pathology Science 3:75-82. (In Persian with English summary).

7. Amzalek E. and Cohen Y. 2007.Comparative efficacy of systemic acquired resistanceinducing compounds against rust infection in sunflower plants. Phytopathology 97:179-186.

8. Audenaert K., Pattery T., Cornelis P. and Hofte M. 2002. Induction of systemic resistance to Botrytis cinerea in tomato by Pseudomonas aeruginosa 7NSK2: Role of salicylic acid, pyochelin, and pyocyanin. Molecular Plant-Microbe Interaction 15:1147-1156.

9. Azami-Sardooei Z., Seifi H. S., De Vleesschauwer D. and Höfte M. 2013. Benzothiadiazole (BTH)-induced resistance against Botrytis cinerea is inversely correlated with vegetative and generative growth in bean and cucumber, but not in tomato. Australasian Plant Pathology 42:485-490.

10.Azami-Sardooei Z. 2011. Induction of resistance to Botrytis cinerea in tomato, bean and cucumber by Serratia plymuthica and plant activators. Ph.D thesis, Ghent University, Belgium, 150p.

11.Azami-Sardooei Z., França S. C., De Vleesschauwer D. and Höfte M. 2010. Riboflavin induces resistance against Botrytis cinerea in bean, but not in tomato, by priming for a hydrogen peroxide-fueled resistance response. Physiological and Molecular Plant Pathology 75:23-29.

12.Azami-Sardooei Z., and Höfte M. 2009. Potential of BTH to induce resistance against Botrytis cinerea in tomato, bean and cucumber. 61th International Symposium on Crop Protection, May 19, 2009, Gent, Belgium.

13.Baysal Ö, Turgut C, and Mao G.2005. Acibenzolar-S-methyl induced resistance to Phytophthora capsici in pepper leaves. Biologia Plantarum 49:599-604.

14.Bokshi A., Morris S. C. and Deverall B. J. 2003. Effects of benzothiadiazole and acetylsalicylic acid on beta- 1,3- glucanase activity and disease resistance in potato. Plant Pathology 52:22-27.

15.Bovie C., Ongena M., Thonart P. and Dommes J. 2004. Cloning and expression analysis of cDNAs corresponding to genes activated in cucumber showing systemic acquired resistance after BTH treatment. BMC Plant Biology 4:15. 
مرورى بر كاربرد بنزوتياديازول در مديريت بيمارى هاى كياهى

Plant Pathology Science (ISSN:2251-9270) Yasouj University,RICeST \& ISC (Iran) Vol. 6(2), 2017

16.Brisset M. N., Cesbron S., Thomson S. V. and Paulin J. P. 2000. Acibenzolar- Smethyl induces the accumulation of defense-related enzymes in apple and protects from fire blight. European Journal of Plant Pathology 106:529-536.

17.Boughton A. J., Kelli H. and Gary W. F. 2006. Impact of chemical elicitor applications on greenhouse tomato plants and population growth of the green peach aphid, Myzus persicae. Entomologia Experimentalis et Applicata 120:175-188.

18.Buschmann H., Fan Z. W. and Sauerborn J. 2005. Effect of resistance-inducing agents on sunflower (Helianthus annuus L.) and its infestation with the parasitic weed Orobanche cumana Wallr. Journal of Plant Diseases and Protection 112:386-397.

19.Buzi A., Chilosi G. and Magro P. 2004. Induction of resistance in melon seedlings against soil-borne fungal pathogens by gaseous treatments with methyl jasmonate and ethylene. Journal of Phytopathology 152:491-497.

20.Choh Y., Ozawa R. and Takabayashi J. 2004. Effects of exogenous jasmonic acid and benzo $(1,2,3)$ thiadiazole-7-carbothioic acid-S-methyl ester (BTH), a functional analogue of salicylic acid, on the egg production of a herbivorous mite Tetranychus urticae (Acari:Tetranychidae). Applied Entomology and Zoology 39:311-314.

21.Chinnasri B., Sipes B. and Schmitt D. 2003. Effects of acibenzolar-s-methyl application to Rotylenchulus reniformis and Meloidogyne javanica. Journal of Nematology 35:110.

22.Chinnasri B., Sipes B. and Schmitt D. 2006. Effects of inducers of systemic acquired resistance on reproduction of Meloidogyne javanica and Rotylenchulus reniformis in pineapple. Journal of Nematology 38:319.

23.Desmond O. J., Manners J. M., Schenk P. M., Maclean D. J. and Kazan K. 2008. Gene expression analysis of the wheat response to infection by Fusarium pseudograminearum. Physiological and Molecular Plant Pathology 73:40-47.

24.Dinh S., Joyce D. C., Irving D. E. and Wearing A. H. 2008. Effects of multiple applications of chemical elicitors on Botrytis cinerea infecting Geraldton waxflower. Australasian Plant Pathology 37:87-94.

25.Faessel L., Nassr N., Lebeau T. and Walter B. 2008. Effects of the plant defence inducer, acibenzolar-S-methyl, on hypocotyl rot of soybean caused by Rhizoctonia solani AG-4. Journal of Phytopathology 156:236-242.

26.Friedrich L., Lawton K., Ruess W., Masner P., Specker N., Gut M.R., Meier B., Dincher S., Staub T., Uknes S., Metraux J.P., Kessmann H. and Ryals J. 1996. A benzothiadiazole derivative induces systemic acquired resistance in tobacco. Plant Journal 10:61-70.

27.Gorlach J., Volrath S., Knauf- Beiter G., Hengy G., Beckhove U., Kogel K. H., O ostendorp M., Staub T., Ward E. and Kessmann H. 1996. Benzothiadiazole, a novel class of inducers of 
systemic acquired resistance, activates gene expression and disease resistance in wheat. The Plant Cell 8:629-643.

28.Hukkanen A., Kokko H., Buchala A., Yrinen J. and Renlampi S. 2008. Benzothiadiazole affects the leaf proteome in arctic bramble (Rubus arcticus). Molecular Plant Pathology 9:799-808.

29.Iriti M. and Faoro F. 2003. Does benzothiadiazole-induced resistance increase fitness cost in bean. Journal of Plant Pathology 46:265-270.

30.Iriti, M., Mapelli S. and Faoro F. 2007. Chemical-induced resistance against post-harvest infection enhances tomato nutritional traits. Food chemistry 105:1040-1046.

31.Kumar S., Thind T. S., Bala A. and Gupta A. K. 2011. Induced resistance in potato against Phytophthora infestans using chemicals and bio-agents. Plant Disease Research 25:12-18.

32.Kusumoto D., Goldwasser Y., Xie X., Yoneyama K., Takeuchi Y. and Yoneyama K. 2007. Resistance of red clover (Trifolium pretense) to the root parasitic plant Orobanche minor is activated by salicylate but not by jasmonate. Annals of Botany 100:537-544.

33.Lang J. M., Gent D. H. and Schwartz H. F. 2007. Management of Xanthomonas leaf blight of onion with bacteriophages and a plant activator. Plant Disease 91(7): 871-878.

34.Liu H., Jiang W., Bi Y. and Luo Y. 2005. Postharvest BTH treatment induces resistance of peach (Prunus persica L. cv. Jiubao) fruit to infection by Penicillium expansum and enhances activity of fruit defense mechanisms. Postharvest Biology and Technoligy 35:263269.

35.Lawton K., Friedrich L., Hunt M., Weymann K., Delaney T., Kessmann H., Staub T., and Ryals J. 1996. Benzothiadiazole induces disease resistance in Arabidopsis by activation of the systemic acquired resistance signal transduction pathway. Plant Journal 10:71-82.

36.Lyon G. D., Reglinski T. and Newton A. C.1995. Novel disease control compounds: The potential to 'immunize' plants against infection. Plant Pathology 44:407-427.

37.Maffi D., Iriti M. and Pigni M. 2010. Uromyces appendiculatus infection in BTH-treated bean plants: Ultrastructural details of a lost fight. Mycopathologia 171:209-221.

38. Mehrabipour S., Abdollahi H. and Ghasemi A. 2010. Response of some quince (Cydonia oblanga Mill.) genotypes from Guilan and Khorasan provinces to fireblight disease. Seed and Plant Improvement Journal 28:67-84.

39.Mondal A. H., Nehl D. B. and Allen S. J. 2005. Acibenzolar-S-methyl induces systemic resistance in cotton against black root rot caused by Thielaviopsis basicola. Australasian Plant Pathology 34:499-507.

40.Pieterse C. M. J., Leon-Reyes A., Van der Ent S. and Van Wees S. C. M. 2009. Networking by small-molecule hormones in plant immunity. Nature Chemical Biology 5:308-316. 


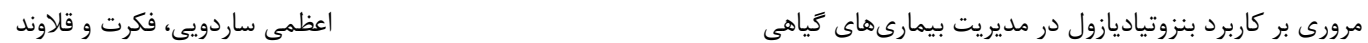

Plant Pathology Science (ISSN:2251-9270) Yasouj University,RICeST \& ISC (Iran) Vol. 6(2), 2017

41.Ruess W., Mueller K., Knauf-Beiter G., Kunz W. and Staub T. 1996. Plant activator CGA 245704: An innovative approach for disease control in cereals and tobacco. Proceedings of the Brighton Crop Protection Conference, 53-60.

42. Terry L. A. and Joyce D. C. 2000. Suppression of grey mould on strawberry fruit with the chemical plant activator acibenzolar. Pest Management Science 56(11): 989-992.

43. Veronesi C., Delavault P. and Simier P. 2009. Acibenzolar- S- methyl induces resistance in oilseed rape (Brassica napus L.) against branched broomrape (Orobanche ramose L.). Crop Protection 28:104-108.

44.Wang D., Pajerowska-Mukhtar K., Hendrickson Culler A. and Dong X. 2007. Salicylic acid inhibits pathogen growth in plants through repression of the auxin signaling pathway. Current Biology 17:1784-1790.

45.Yi H. S., Yang J. W., Choi H. K., Ghim S. Y. and Ryu, C. M. 2012. Benzothiadiazoleelicited defense priming and systemic acquired resistance against bacterial and viral pathogens of pepper under field conditions. Plant Biotechnology Reports 6:373-380. 